\title{
Biomimicry in French Urban Projects: Trends and Perspectives from the Practice
}

\author{
Eduardo Blanco ${ }^{1,2, * \mathbb{D}}$, Estelle Cruz ${ }^{2}$, Chloé Lequette $^{2}$, Kalina Raskin ${ }^{2}$ and Philippe Clergeau ${ }^{1}$ \\ 1 Centre d'Écologie et des Sciences de la Conservation (CESCO UMR7204), MNHN, CNRS, \\ Sorbonne Université, BP 135, 57 rue Cuvier, 75005 Paris, France; philippe.clergeau@mnhn.fr \\ 2 Ceebios, 62 rue du Faubourg Saint-Martin, 60300 Senlis, France; estelle.cruz@ceebios.com (E.C.); \\ chloe.lequette@ceebios.com (C.L.); kalina.raskin@ceebios.com (K.R.) \\ * Correspondence: eduardo.blanco@ceebios.com
}

check for updates

Citation: Blanco, E.; Cruz, E.; Lequette, C.; Raskin, K.; Clergeau, P. Biomimicry in French Urban Projects: Trends and Perspectives from the Practice. Biomimetics 2021, 6, 27. https://doi.org/10.3390/ biomimetics 6020027

Academic Editor: Ille C. Gebeshuber

Received: 26 February 2021

Accepted: 23 April 2021

Published: 27 April 2021

Publisher's Note: MDPI stays neutral with regard to jurisdictional claims in published maps and institutional affiliations.

Copyright: (c) 2021 by the authors. Licensee MDPI, Basel, Switzerland. This article is an open access article distributed under the terms and conditions of the Creative Commons Attribution (CC BY) license (https:// creativecommons.org/licenses/by/ $4.0 /)$.

\begin{abstract}
Biomimicry is a design framework with growing interests in sustainable architectural and urban design practice. Nevertheless, there is a significant lack of studies and knowledge regarding its practical application. In 2020, a French workgroup called Biomim'City Lab published a document identifying and describing 16 urban projects designed by French teams integrating biomimicry at various levels. Our research is an opportunistic study analyzing this data, aiming to identify trends and challenges in the French market. We analyzed the projects using a mixed-method approach, through quantitative typological analysis and qualitative narrative analysis. This sample of French projects indicates a trend of increasing interest in biomimicry on built space projects in France. Biomimicry was primarily applied at the façade/roof/soil systems, mostly using macroscopic models as ecosystems, plants, and animals. Designers declared to aim diverse objectives with the biomimetic approach; still, thermal comfort is the most recurrent in the sample. We also identified that challenges remain to foster the field application, as the lack of awareness of the urban fabric stakeholders on the topic and the gaps between research and design practice.
\end{abstract}

Keywords: biomimicry; architecture; urban design; French urban projects

\section{Introduction}

Biomimicry draws upon emulation of, and knowledge transfer from, living organisms and whole ecosystems to find solutions to human problems [1]. In the built environment sciences, it is a growing topic [2-4], with an application that mainly aims for sustainable innovation [3,5]. Biomimicry offers an opportunity to operationalize sustainability and regenerative development on architectural and urban projects $[2,6]$.

The practice of biomimetic architecture faced the first increase throughout the nineties, within the beginning of a global context of energy transition, giving birth to iconic biomimetic projects like the Eastgate building (1996) [2,5]. With the simultaneous development of biomimetic architecture in research, education, and architectural practice, the last two decades presented a surge of interest in the topic [7].

In Europe, biomimicry has been highlighted by the European Commission as an opportunity for research and innovation, with potential contributions to tackle climate change adaptation and mitigation [8]. Furthermore, some European research institutions focus on advancing the theory and practice of biomimicry in architectural and urban design. In Germany, the Universities of Stuttgart, Freiburg, and Tübingen have jointly dedicated efforts to develop and test biomimicry applications through the trans-regional Collaborative Research Center "Biological Design and Integrative Structures" SFB-TRR 141 [9]. In France, the French National History Museum created in 2019 the Bioinspire-Museum project to coordinate and promote bioinspiration throughout its activities, highlighting architectural and urban design applications of their biological and ecological knowledge [10]. In the 
Netherlands TU Delft has specialized teaching in the topic and hosted relevant research regarding biomimetic architectural design [11].

In France, biomimicry is a growing field of innovation. Since 2015 local stakeholders organize a national congress on biomimicry (Biomim'Expo), to showcase national emerging projects and research on the topic. In architecture and urban design, a collaborative workgroup of biomimicry practitioners was launched in 2019, called Biomim'City Lab. This collective, animated by Ceebios (a not-for-profit French network and center of expertise on biomimicry), integrates ten different French stakeholders of the urban fabric, as architects, real estate developers, consulting companies, and research institutions (in alphabetical order: Bechu \& Associés, Ceebios, Eiffage, Elan, Icade, In Situ Architecture, New Corp Conseil, Nobatek/INEF 4, Renault, and Tangam Architectes). They all have experimented at some level biomimicry in their projects, aiming at sustainable development. This workgroup focus on increasing skills, co-developing new tools, and sharing expertise within the French context.

In 2020, one year after its creation, the Biomim'City Lab published an online report called "Projets urbains bio-inspirés: un état des lieux des projets français" (Bio-inspired urban projects: an inventory of French projects, available only in French in the Supplementary Materials). This report documented, in standard factsheets, sixteen French projects that have integrated biomimicry and bio-inspired approaches at different levels on urban projects dating from 2007 to 2019 . The report presents the collected data, results, and feedback from the design teams from a sample of bio-inspired projects in architecture and urban design in France. The report is a communication and awareness-raising tool for practitioners to enhance biomimicry development in France [12].

The report is different from any other previous scientific and non-scientific publications regarding its objectives and data. Previously published thematic reports had only a few projects briefly presented [13]. In the academic field, few studies documented and explored the practice of biomimicry $[11,14,15]$. Hayes et al. (2019) realized one of the few available cases studies, focusing on six system-level biomimicry urban projects, but none of them from a European context. Furthermore, the analyzed projects in their study were not identified either deeply described.

The sixteen documented projects from the "Bio-inspired urban projects: an inventory of French projects" report were selected by the BiomimCity'Lab stakeholders, following each stakeholder own preferences. The only criteria among all projects were that they had to integrate at some level a biomimetic approach and be situated in France or be designed by French teams. As a result, the analyzed projects vary in form, size, objective, status, and biomimicry application level. Furthermore, the report is not an exhaustive study of the French biomimetic urban projects, but it constituted an unprecedented sample worth analyzing. Several documented projects are proposals for architectural and urban design competitions, and the report includes projects that were not successful in the process.

As a significant lack of studies and knowledge regarding biomimicry's design practice applied to architectural and urban designs remains [16], our research carried out an opportunistic analysis of this French biomimetic practice sample, relying on all of the sixteen projects factsheets produced by the Biomim'City Lab. This study is an opportunity to through lights on the contemporary trends in the practice and challenges that design teams face integrating biomimicry.

In this context, the research questions we have explored are:

- What types of urban biomimetic projects did French teams design?

- How was the biomimetic approach expressed in these projects in terms of goals, biological models and integration level?

- What challenges did the design teams face on the design process? 


\section{Materials and Methods}

\subsection{Data Collection}

As an opportunistic study, this research did not produced data, but data from the sixteen biomimetic French urban projects presented in the source document ("Projets urbains bio-inspirés: un état des lieux des projets français", Biomim'City Lab, Paris, France, Document S1) were extracted and analyzed. All the French case studies document by the Biomim'City Lab report are here analyzed. Table 1 presents context information about these projects. Table S1 presents all the collected data. They have different understandings in terms of sustainability, comprehension, and abstraction of living systems, not evaluated in this study. However, they all derived from a creative approach based on the observation of biological systems.

Table 1. Analyzed projects.

\begin{tabular}{lll}
\hline \multicolumn{1}{c}{ Project Name } & \multicolumn{1}{c}{ Project Location } & Design Year \\
\hline Alguesens & Paris, France & 2016 \\
Bangkok I'm Fashion Hub & Bangkok, Thailand & 2015 \\
Biolum_Reef & Marseille, France & 2017 \\
CIRC Lyon & Lyon, France & 2018 \\
Quartier de Gally (Cité Fertile- & & 2018 \\
Terres de Versailles) & Versailles, France & 2013 \\
Ecoquartier Smartseille & Marseille, France & 2017 \\
Ecotone & Arcueil, France & 2014 \\
Eglise de Nianing & Nianing, Senegal & 2019 \\
Estran & Biarritz, France & 2010 \\
Groupe Scolaire des Sciences & & 2019 \\
et de la biodiversité & Boulogne-Billancourt, France \\
Osez Joséphine & Rueil Malmaison, France & 2013 \\
Parramata & Parramata, Australia & 2019 \\
Pôle d'Excellence sur le Biomimétisme Marin & Biarritz, France & 2018 \\
Residence solaire d'Ordener & Senlis, France & 2012 \\
Skolkovo Innovation Center & Skolkovo, Russia & 2007 \\
Tour D2 & Paris, France & \\
\hline
\end{tabular}

Table 2 provides an overview of the variables and classification options used in the study, extracted from each project factsheet and compiled on a Microsoft Office Excel 365 database (Microsoft Corporation, Redmond, WA, USA). To make data scientifically sound with our research questions, we merged some of the original classes from the factsheets for the variables "project status", "project type", "integration level of the biomimetic approach", and "biological model". Document S2 explains each of the classification variables and options.

\subsection{Analysis}

Results were analyzed with a mixed-method approach, using quantitative and qualitative perspectives. At first, we use correlational research, relying on a quantitative typological analysis [17], to explore the sample trends. Following, we used a qualitative narrative and content analysis of text excerpts from the report $[17,18]$. This step aimed to explore lessons and barriers from the designing team perspective. Both approaches are detailed in the sequence:

\subsubsection{Typological Analysis}

The typological analysis aims to identify significant trends in the sample, such as their chronological evolution, project types, aimed objectives, level of integration and types of biological models. After data collection, we quantitively analyzed data on Microsoft Office Excel 365 (Microsoft Corporation, Redmond, WA, USA), using frequency and chronological analysis. 
Table 2. Collected data from the original factsheets with the classification options used in the study.

\begin{tabular}{|c|c|}
\hline Variables & Classification Options \\
\hline Year of design & - \\
\hline Project Status & $\begin{array}{l}\text { Accepted and constructed or under construction I Accepted but not } \\
\text { constructed I Not Accepted. }\end{array}$ \\
\hline Type of project & Housing | Equipment I Office I Mixed-use. \\
\hline Renovation & Partial renovation on the project I No renovation \\
\hline Aimed objectives with the biomimetic approach & $\begin{array}{l}\text { Thermal comfort | Visual/lighting comfort | Acoustic comfort | Indoor air } \\
\text { quality | Outdoor air quality | Resistance to mechanical stress | Indoor water } \\
\text { management | Outdoor water management | Biodiversity hosting | Adaptation } \\
\text { to climate change | Lightening of the structure | Waste management | Others }\end{array}$ \\
\hline Integration level of the biomimetic approach & $\begin{array}{l}\text { Materials | Technology | Façade/roof/floor } \\
\text { system I Building | Plot/Neighborhood. }\end{array}$ \\
\hline Type of biological model & $\begin{array}{l}\text { Eukaryote-Animal I Eukaryote_Plant I Eukaryote- } \\
\text { Fungi | Archaea/Bacteria I Ecosystem }\end{array}$ \\
\hline Aimed labels and certifications families & $\begin{array}{l}\text { Batiment passif | BDM | BiodiverCity I BREEAM | Cradle to } \\
\text { Cradle I E+C- I Effinergie I HQE I LBC I LEED | Matériaux } \\
\text { biosourcés | Nature-Art-Education I NF Habitat | RT2012 | WELL }\end{array}$ \\
\hline Lessons learned and challenges & Text excerpts (Document S3) \\
\hline
\end{tabular}

\subsubsection{Content Analysis}

Content and narrative pattern analysis have been done using text excerpts of the original report. Each project factsheet concluded with a section named "Lessons learned" (Leçons à retenir), in which designing and editorial teams highlighted main challenges, levers and barriers to the realization of a biomimetic urban project. We extracted these full excerpts from each factsheet and composed a unique textual corpus for analysis.

The textual corpus (Document S2) was then imported to MaxQDA Analytics Pro 2020 (VERBI GmbH, Berlin, Germany). We first used the word cloud function on this software to identify recurrent terms in the corpus. Afterwards, we used the interactive word tree function to explore phrases and narratives around the most frequent word, understand the context, and draw insights from this data.

\subsection{Methodological Limits}

This research is an opportunistic study, and some of its limits reflect the limits of the original data source. Notably, the French report does not document all biomimetic urban projects designed in France, but some of them. Nevertheless, we consider it a representative sample that allows us to infer trends in practice, once it is the most updated information available. Furthermore, this research does not aim to evaluate the pertinence and the environmental performance of the projects and their biomimetic design approach.

\section{Results}

\subsection{Project Status and Types}

We identified that $44 \%(n=7)$ of the projects have been accepted by the project owners and are built or under construction. Examples in this category are the Nianing Church, a concluded project located in Senegal (Figure 1). This project finds inspiration in the termite mounds model aiming at passive thermal regulation, a well-described biological model successfully applied in previous projects as the $\mathrm{CH} 2$ and the Eastgate Center [5]. Another example is the Quartier de Gally project, a neighborhood under construction that aims at natural ecosystems as models to promote a neighborhood that better integrate urban spaces and nature. 


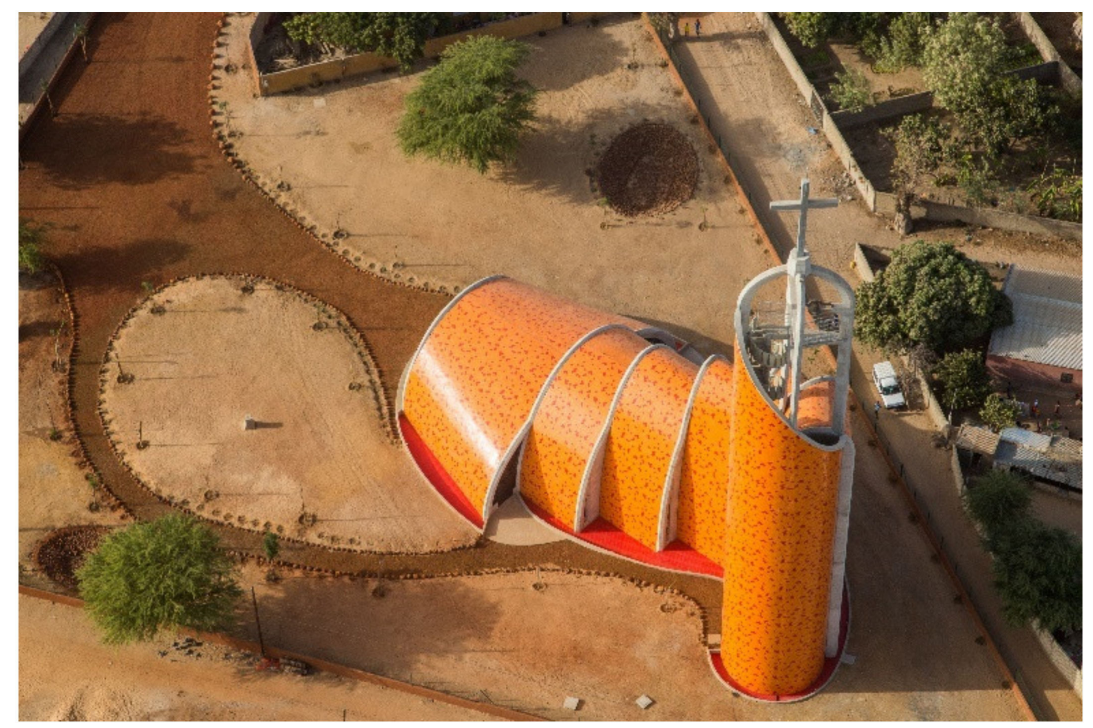

Figure 1. Nianing Church, Sénégal ( Régis L’Hostis/IN SITU Architecture).

A quarter of the projects $(n=4)$ have been accepted but are not constructed and not under construction. It includes conceptual projects, as the Biolum_Reef, a project that aims to create autonomous human habitat in the sea, presenting bioluminescent bio-inspired technologies and contributing to ocean decontamination and natural habitat provision (Figure 2). This category includes also projects accepted by the client and further abandoned, as the Residence Solaire d'Ordener, a project in which the building orientations were calculated using a solar phyllotaxis algorithm to optimize sunlight exposition, and, finally, projects still in executive design, as the Ecotone project that finds inspiration in transition ecosystems recreating ecosystems services in the urban space.

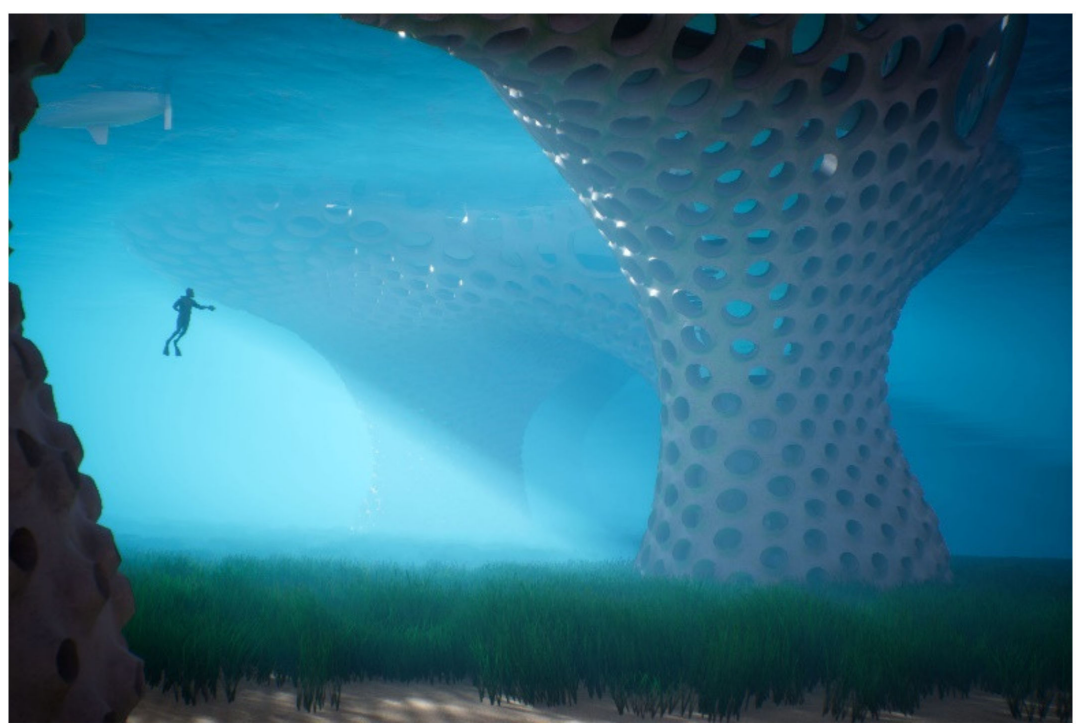

Figure 2. Biolum_Reef (@ Treex/Tangram Architectes).

Furthermore, $31 \%(n=6)$ of the projects were not accepted by the project owners. One example is the Osez Josephine project, a mixed-use project that finds inspiration in French forests, aiming for diverse vegetation strategies, more circular water and waste cycles and bioclimatic and evolutive buildings.

Office projects are the most represented (37\%), followed by equipment projects (25\%), as schools and churches (Figure 3). Housing and mixed-use projects are the less represented types (19\% each). Office projects mostly implemented biomimetic approaches, but they 
also represents the project type with more issues to reach implementation phases (Figure 3). One successful office example is the Tour D2 project, which uses the periosteum structure (membrane covering the bones) as model for its exo-structure, which allowed to reduce the total building mass (Figure 4). An example that did not reach the implementation phase is the Parramatta project, which uses a local eel species model for a passive thermal regulation system.

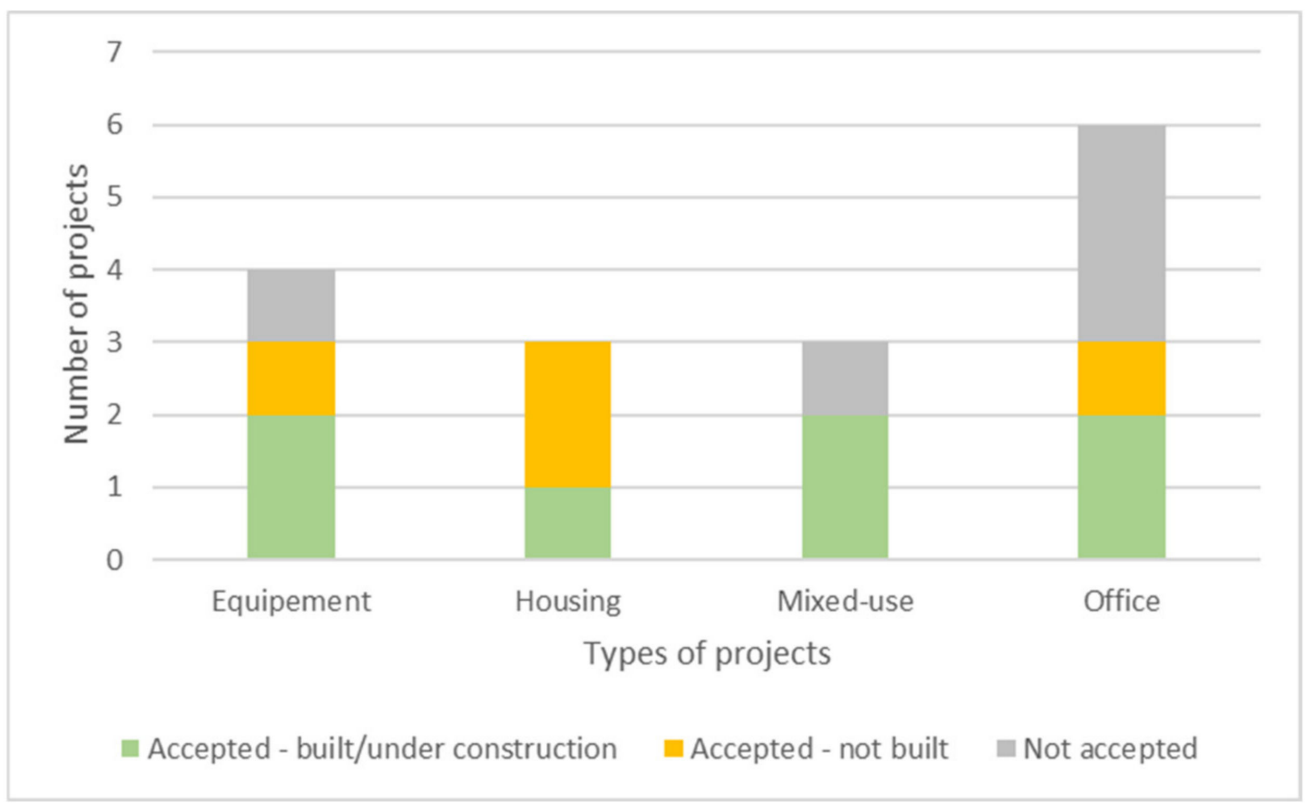

Figure 3. Distribution of projects status according to their types.

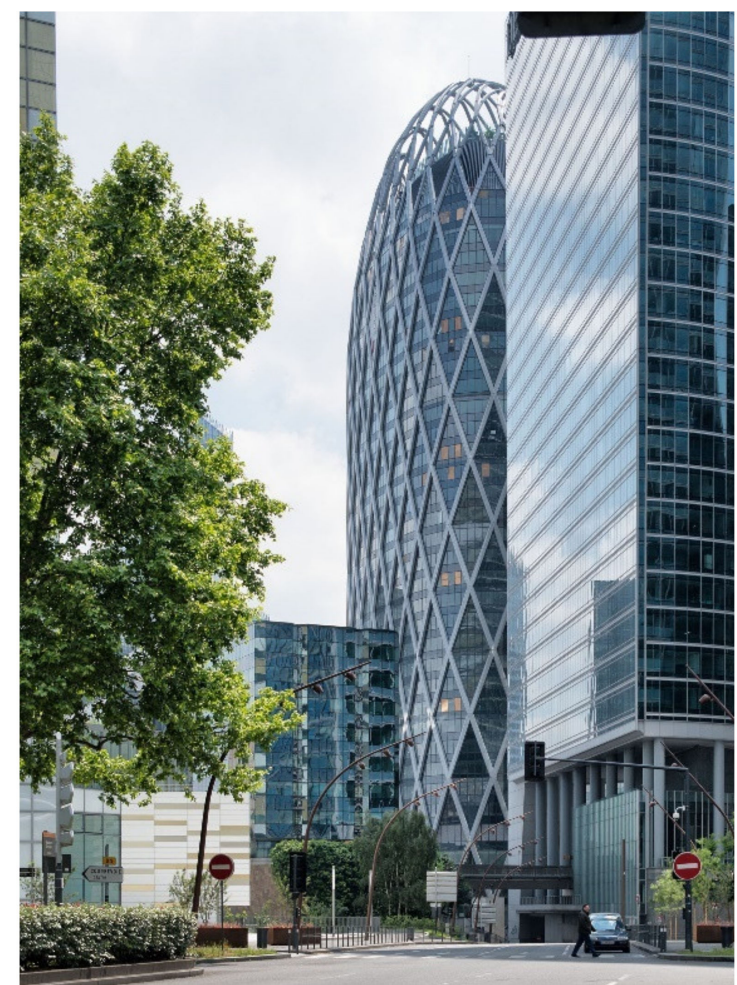

Figure 4. Tour D2, La Défense, Paris (@ Pierre Elie de Pibrac/Bechu \& Associés). 
Very few of them addressed the retrofit of existing infrastructures. Only 13\% $(n=2)$ integrate some renovation. They are the Osez Josephine and the Quartier de Gally projects. In both, renovations were partial, on some selected pre-existing buildings.

\subsection{Chronological Evolution of Projects}

Figure 5 outlines this sample distribution over time and according to their design year and status. The oldest documented project in the report was designed in 2007. Between 2012 and 2016, the report presents at least one biomimetic project designed per year. Then, the number increases from 2017 to 2019. Nevertheless, since 2013, we also observe an increasing number of projects that did not reach implementation (not built or not accepted).

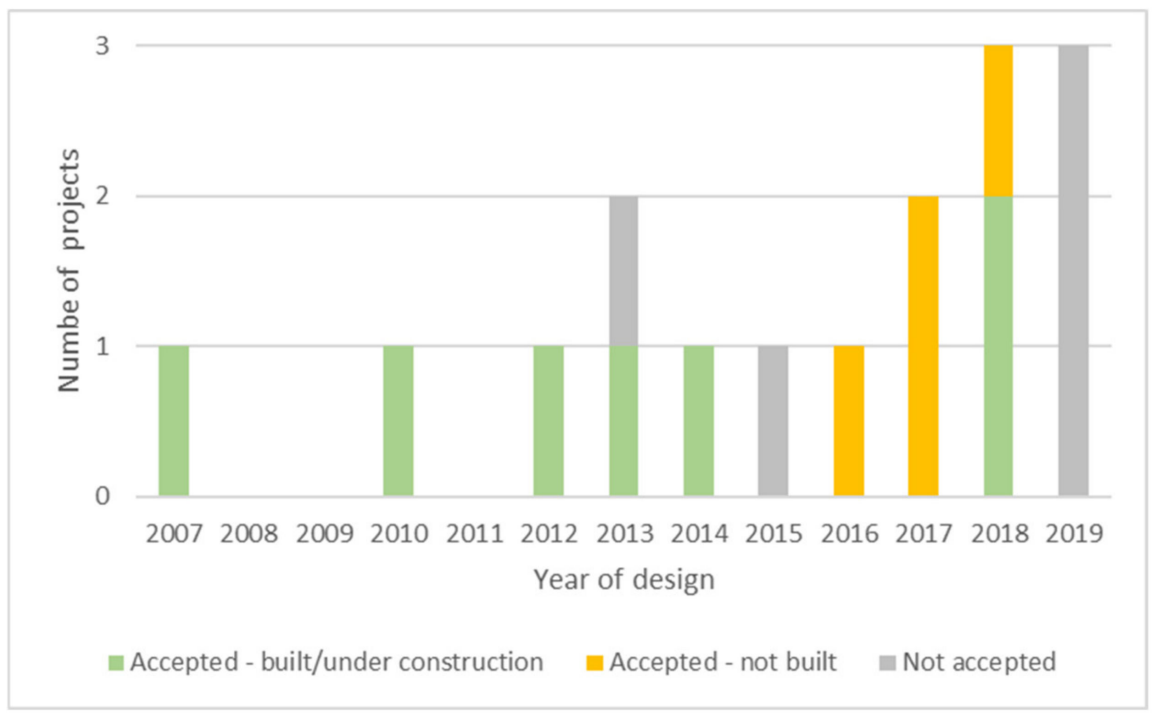

Figure 5. Distribution of the analyzed biomimetic urban projects according to their status and design date.

\subsection{Objectives}

Figure 6 presents the frequency of declared objectives of the projects with their biomimetic approach. We can observe that six objectives were present in more than ten projects (62.5\% of the sample): climate change adaptation, biodiversity hosting, outdoor water management, indoor air quality, visual and lighting comfort, and thermal comfort.

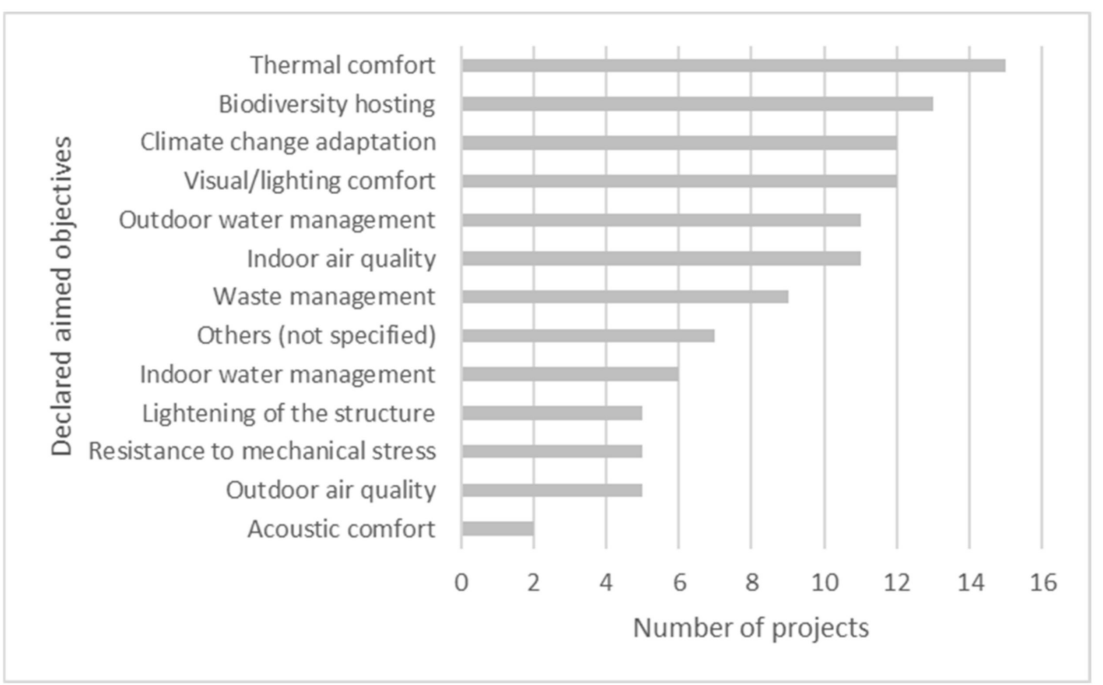

Figure 6. Aimed objectives. 
Most of the projects declared to seek several objectives with their biomimetic approach. The average number of objectives aimed per project was 7 . The project with a narrower focus is the CIRC, a project that uses bio-inspired adaptative solar protections made of metal with shape memory, aiming for visual and light comfort, and thermal comfort (Figure 7). The projects with a wider focus in the sample, aiming twelve different objectives are the Biolum_Reef, Osez Joséphine and the Pôle d'excellence sur le biomimétisme marin.

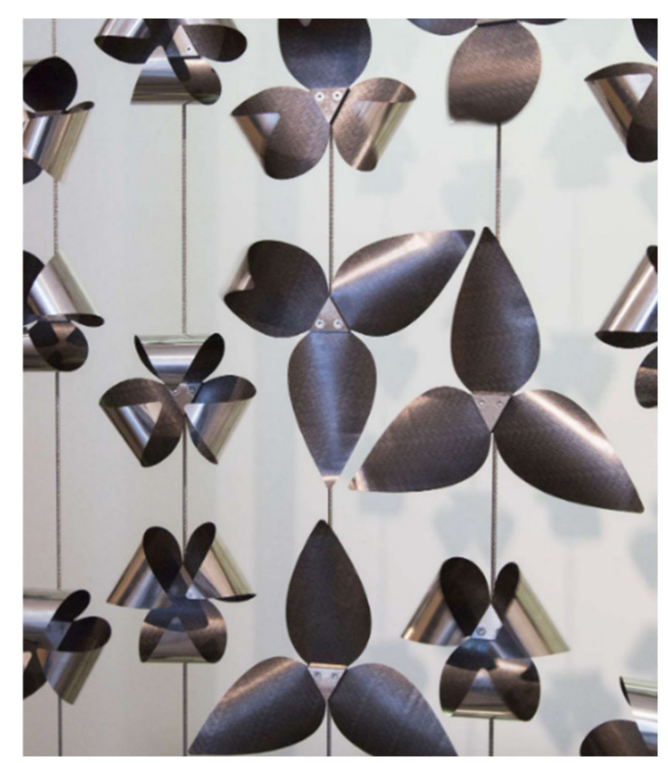

Figure 7. CIRC adaptative solar protections (@ Art\&Build).

We observe that accepted and built or under construction projects in the sample tend to have a narrow focus on their objectives (Figure 8).

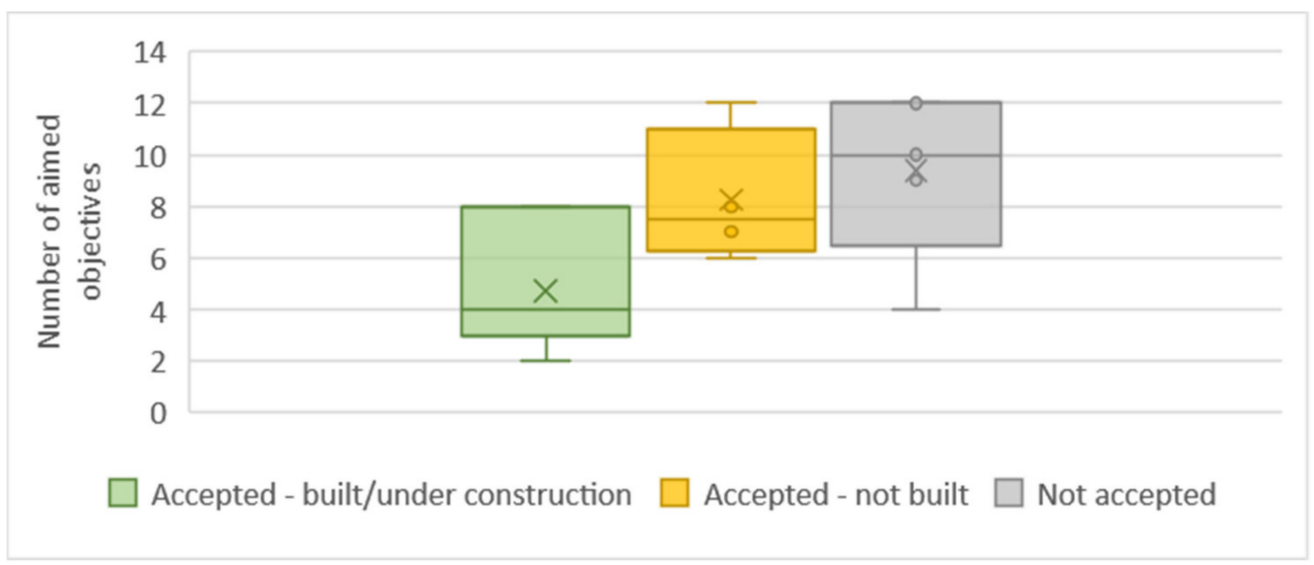

Figure 8. Distribution of the total number of aimed objective in the projects per project status.

\subsection{Level of Integration}

The projects' most recurrent integration level of the biomimetic approach is at the façade/roof/floor systems (Figure 9). Ten projects applied some level of biomimicry at this level. Examples are the Tour D2 project with its exo-structure, the CIRC with its adaptative solar protections and the Alguesens project, which proposes a bio-façade with algae bioreactors, ensuring building thermal regulation and $\mathrm{CO}_{2}$ sequestration. 


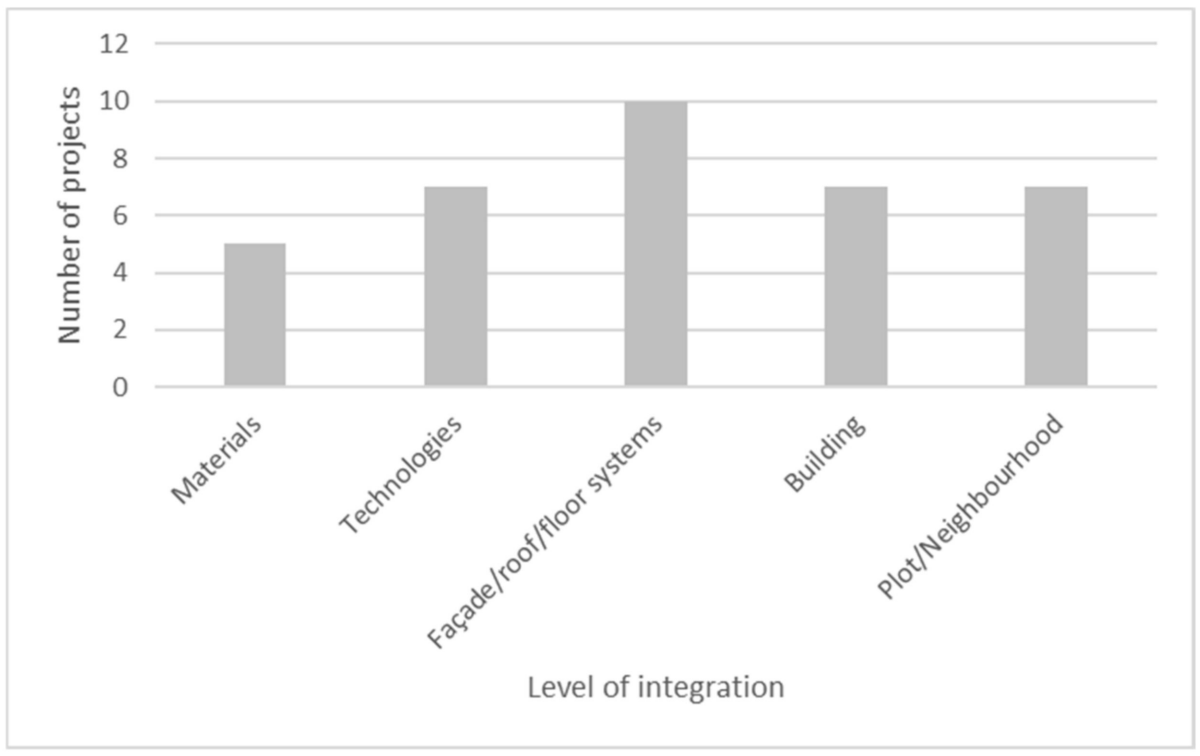

Figure 9. Integration level of the biomimetic approach.

Moreover, the less explored level is building materials (Figure 9). One example is the Bangkok I'm Fashion Hub, which explored a minimal structural surface in local woven bamboo, inspired by spider webs, associated with a bio-inspired membrane ensuring waterproofing and passive ventilation.

At the technology level, one example is the Smartseille project (Figure 10a), which tested a mycelium-based technology to remediate soil pollution on the project site. At the building level, one example is the Estran project, which replicates a foreshore ecosystem in the building, integrating a wetland to serve as a reservoir for rainwater, water treatment system and habitat for biodiversity. Finally, at the plot/neighborhood level, examples are the Quartier de Gally (Figure 10b) and the Ecotone projects.

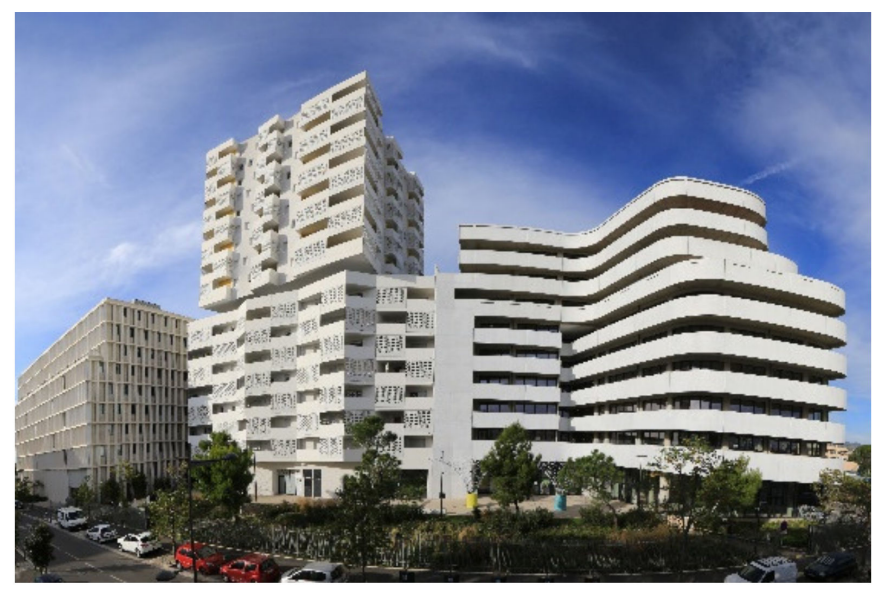

(a)

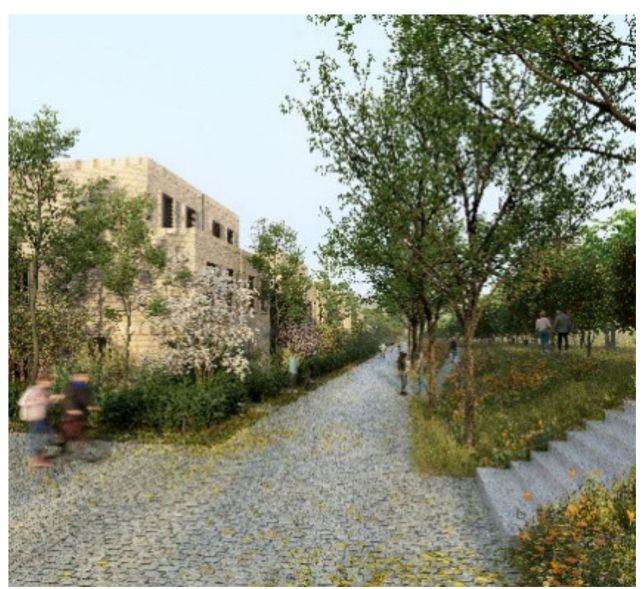

(b)

Figure 10. (a) Smartseille ( Action Photo Video Thierry Lavernos/Eiffage); (b) Quartier de Gally (C ICADE).

On average, projects explore two different levels of integration. Three projects explored just one level (CIRC, Nianing Church and Tour D2), and only one project explored all the dimensions (Pôle d'Excellence sur le Biomimétisme Marin). 


\subsection{Type of Biological Models}

Ecosystems are the most recurrent models, cited in 10 projects, followed by Eukaryotes models as plants and animals. Fungi and Archaea/Bacteria models are the less explored models in our sample (Figure 11).

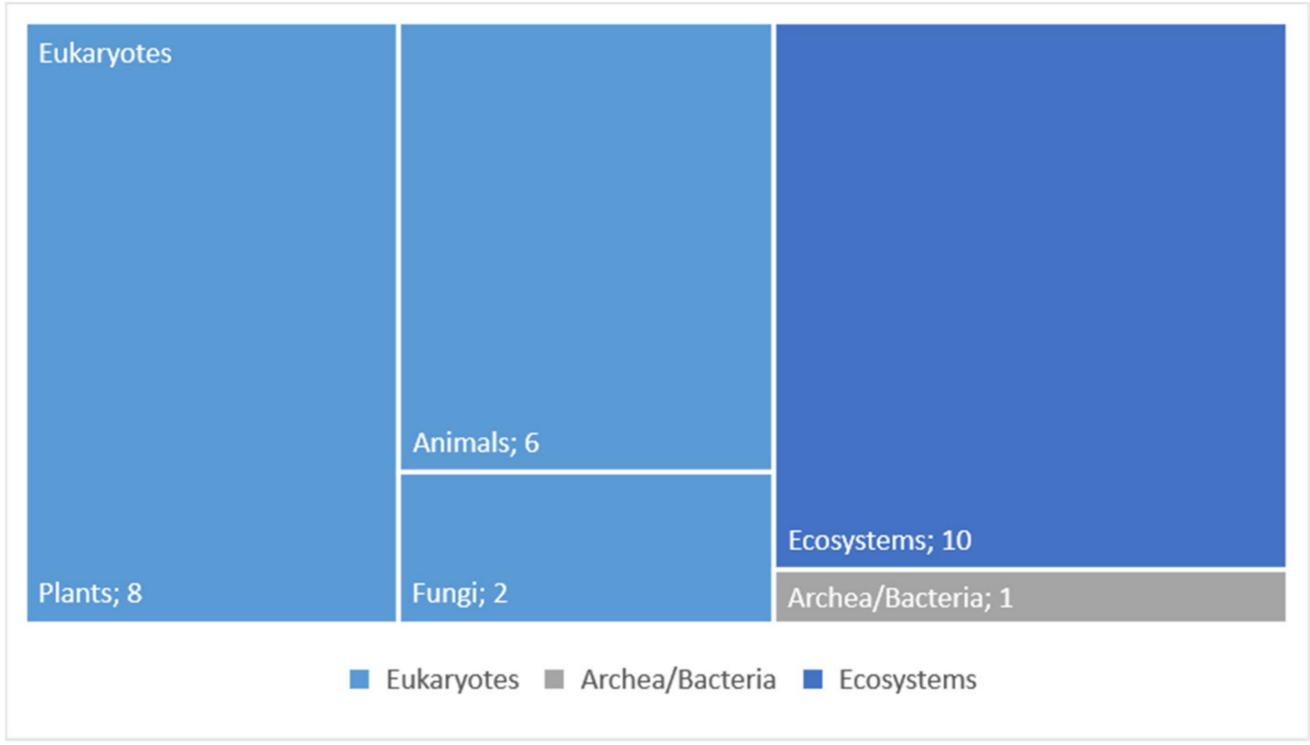

Figure 11. Occurrence of the different types of biological models ( $n=$ number of observations).

\subsection{Green Labels}

To give visibility to their sustainable engagements and performances, ten projects from the sample (62.5\%) highlighted labels that the projects aimed for or obtained. Fifteen different labels families have been cited, but only six have been cited more than once (Figure 12). We can find a higher presence of standard French market label families as $\mathrm{HQE}, \mathrm{E}+\mathrm{C}$ - and BiodiverCity. Nevertheless, innovative labels, not yet fully adopted by the French market, have been observed, as the LBC.

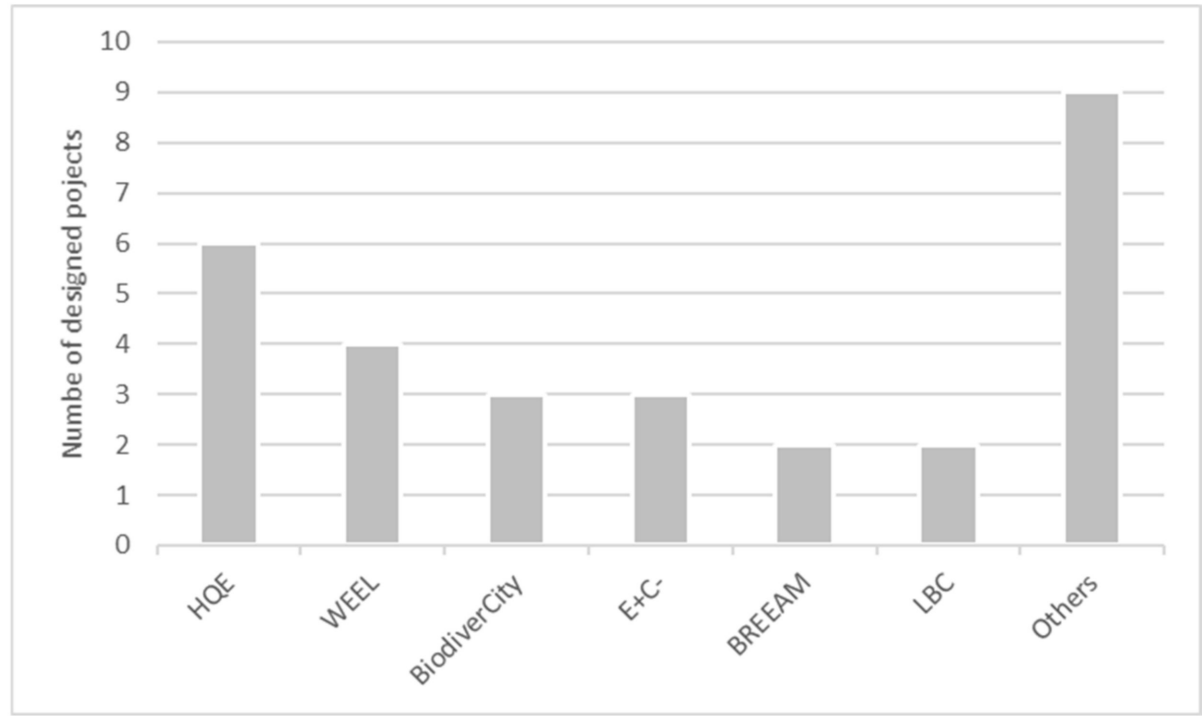

Figure 12. Green building labels. 


\subsection{Design Challenges}

The main recurrent keywords in the "Lessons learned" section from the projects factsheets relates to the design process and its challenges as: "conception" (design), "rechercher" (research), "étude" (study), "temps" (time) and "integration/intégrer" (integration) (Figure 13).

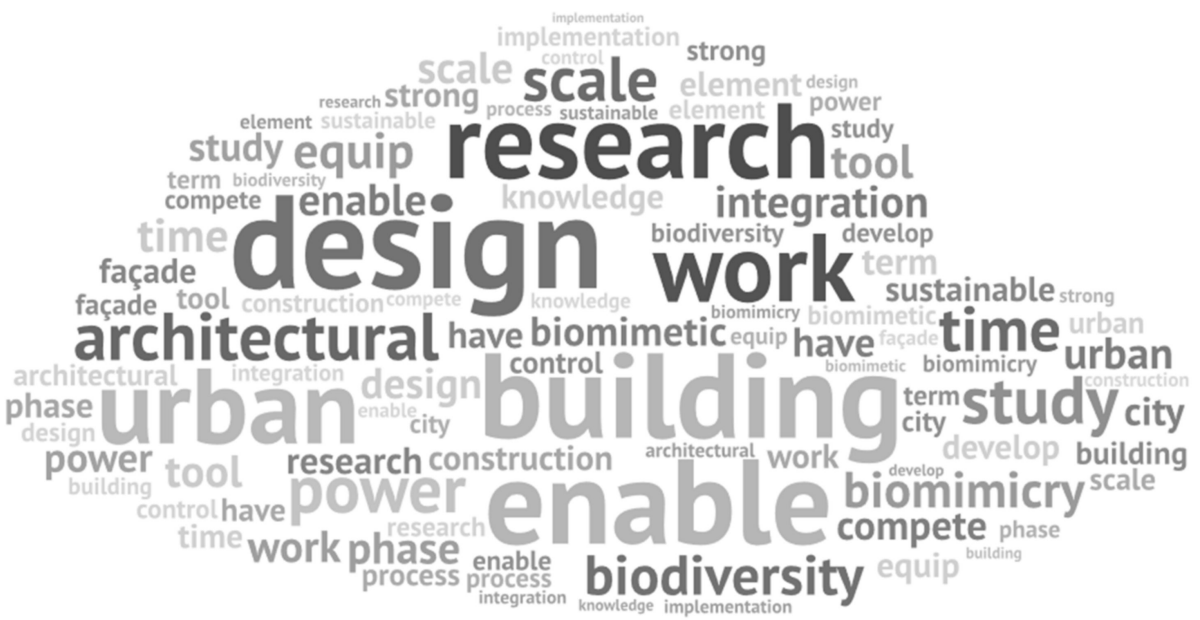

Figure 13. “Lessons learned” section word cloud, using MaxQDA Analytics Pro 2020.

Figure 14 presents the interactive word tree for the word "conception" (design), the main identified keyword. The interactive word tree allowed us to identify passages and recurrent ideas presented by the designing teams.

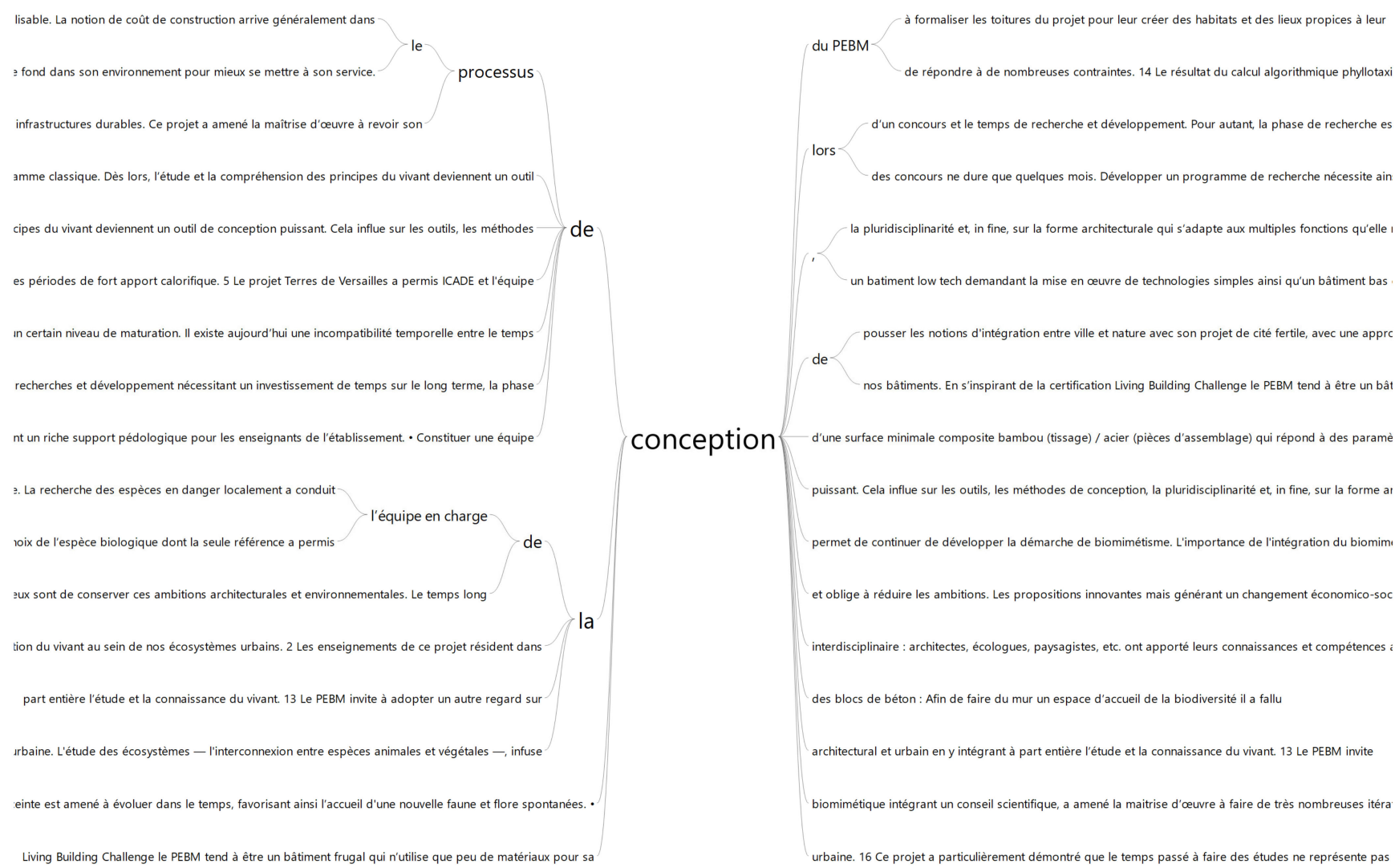

Figure 14. Interactive word tree for "conception" using MaxQDA Analytics Pro 2020. 
The passages related to the challenges of the design process converge into two main topics: project temporality and team knowledge.

The result highlights that the temporalities of design and research process are distinct, as the available time for the design of urban projects, in the French concurrently context, is short. However, the research and development process usually necessary to apply biomimicry into the process is long. Nevertheless, designers acknowledge the importance of bridging the gap between the two practices. The following passages illustrate this:

1. "research and development process at the heart of biomimetic solutions: the bio-inspired facades of the project were the subject of a research project, with several prototypes and tests before being integrated into the project."

2. "The long design time allows the biomimicry approach to continue to be developed."

3. "Today there is a temporal incompatibility between the design time in a competition and the research and development time."

4. "This project has particularly demonstrated that the time spent on studies does not represent a cost, but a real investment (... )."

5. "The limitations of this project are the number of associated research projects that would need to be launched over the long term."

The second challenge is related to the team experience and knowledge of biomimicry, biology and ecology. Designers acknowledge the importance of working in a multidisciplinary context, integrating experts, and building biomimicry capacity on the design team and other project stakeholders. The following passages support this:

1. "The importance of integrating biomimicry right from the competition phase with an acculturation of the architects and the project owner upstream of the project is a key element."

2. "Set up an interdisciplinary design team: architects, ecologists, landscape designers, etc. contributed with their knowledge and skills to build a project (... )."

3. "This project provided an opportunity to explain the biomimetic approach and its potential to the contracting authority. The latter understood the real opportunities that the biomimetic tool offers (...) but we also identified some inherent obstacles related to their poor knowledge on the subject."

4. "This project led the project management to review its architectural and urban design process by integrating the study and knowledge of living things into it."

5. "The process of biomimetic design integrating a scientific council, led the project management to do many iterations and to develop their knowledge on many subjects. In return, the knowledge not directly used has enriched the process allowing the project management to improve its practice."

\section{Discussions}

\subsection{An Increasing Trend over Time}

In the analyzed sample, we observed an increasing trend over time of projects applying biomimicry for sustainable development in France. This trend deserves further exploration with a larger and exhaustive sample. This trend converges with the increase in biomimicry research applied to architecture and urban design in the last years already demonstrated by previous research $[4,5]$. Two important milestones in the French timeline that contributed to more visibility and interest in biomimicry are the Alguesens project (2016) and the Ecotone project (2017). Alguesens is one of the winners of the "Reinventer Paris" competition, aiming to innovate and experiment with new approaches to bring selected Parisian sites to life. Ecotone is one of the winners of the "Inventons la Métropole du Grand Paris" competition, one of Europe largest contemporary competition, promoting innovative projects to rethink critical sites in the Parisian metropole region.

Nevertheless, our sample also presents a growing number of projects that do not reach the implementation phase. Several factors could be related to these projects non-acceptance, not related to the biomimetic approach, as the highly competitive context of urban projects competitions, the quality of the overall project, the project costs, and political preferences. However, the role of the biomimetic approach in the project acceptance by the final client 
deserves further exploration. Hayes et al. (2019) highlighted in their case studies that the absence of well documented and successful application examples remains a significant barrier in the field. Designers from the analyzed projects also indicated that the project owner's lack of understanding of biomimicry could be a barrier to the project success.

\subsection{A Focus on Macroscopic Models}

Most of the analyzed biological models remained at macroscopic scales such as ecosystems and eukaryotes. This finding converges with previous results highlighting a taxonomic bias in selecting biological models [14]. This trend can be explained due to the lack of academic knowledge of biological models by the design team and the lack of time to analyze, compare, and then select relevant living models to face the project challenges. Integrating stakeholders with a strong background in biology or ecology in the design teams can be a way to explore further biological models $[19,20]$, mainly in a short delay design context. Another lever is developing tools and methods to help designers navigate biological knowledge easily, as being explored by fellow researchers as reviewed by Wanieck et al. [21].

Ecosystem-level biomimicry is a growing research topic [4,16], and its first position in our sample highlights a particular interest in the practice for this subject. We assume that ecosystem-level inspiration helps address transversal and systemic urban challenges such as biodiversity loss, the materials, and energy flows between urban and ecological systems $[16,22,23]$.

\subsection{Organising the Design Process}

There is a significant challenge in integrating research and development with urban biomimetic practice [24]. Designing teams highlighted the different temporalities and the positive aspects of integrating research and specialists in the projects. Integrated design process (IDP) could be a helpful design framework to organize biomimetic architectural and urban projects design. It relies on multi-disciplinary teams early engaged in the project, with a straightforward decision-making process and an external facilitator, aiming to foster sustainable and regenerative development on urban projects keeping in mind the project quality and costs [25].

Another leverage point would be to work alongside project owners to raise awareness of the topic and integrate biomimetic specifications on their project briefing and technical specifications.

\subsection{Thermal Comfort and Biodiversity Hosting: Two Major Entry Points}

Thermal regulation is a contemporary urban challenge well-explored in biomimetic architecture and illustrated by numerous well-documented proofs of concept [2,5]. Successful biomimetic cases reduce the risks of rejection for project stakeholders [16]. This could explain the number of observations of this objective within the sample $(n=15)$. Among the analyzed projects, diverse solutions and strategies have been observed to reach this objective through biomimicry. The Skolkovo Innovation Center proposes a site organization that minimizes thermal loss, imitating penguins comportment to save and share heat. Other projects deal with thermal regulation through the façades, as the CIRC and Alguesens, and others with passive ventilation systems as the Nianing Church and Parramatta projects.

Regarding biodiversity, several projects declared to contribute to creating habitat for biodiversity $(n=13)$. However, only one project, the Ecole des Sciences et de la Biodiversité, clearly stated the biomimetic approach to reach this objective. To bring biodiversity back to the urban space and promote human and other species co-habitation, the building walls find inspiration in cliffs walls, using concrete blocks that create holes and niches for different animal and plant species (Figure 15). 


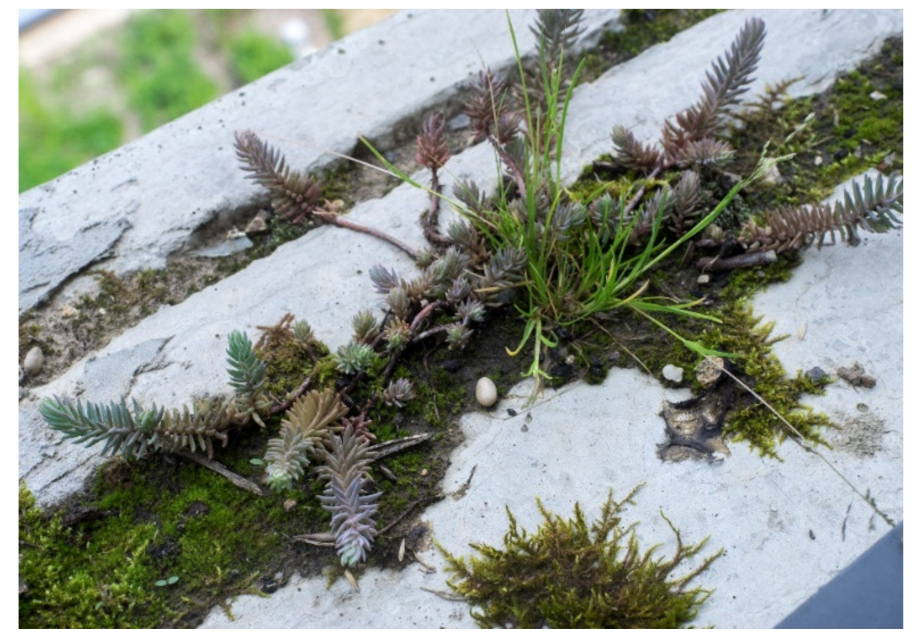

Figure 15. Biodiversity at the walls of Ecole des Sciences et de la Biodiversite (@ Myr Muratet/ChartierDalix).

Even if biodiversity and ecosystems models have a high interest in our sample and practice, very few bio-inspired projects achieve to address their complexity adequately. For example, projects finding inspiration on ecosystems tend to look mainly to materials and energy flows, translating it to into urban metabolism and circular economy solutions. However, the ecosystems biotic and abiotic structure and ecosystems functions are much less explored [22,26], leading to simplistic and metaphorical ecosystem-level biomimicry application.

\subsection{Biomimetics Applied to Retrofit}

The renovation of urban infrastructures remains the main lever over the coming years to reduce human impacts on biodiversity and ecosystems [27]. In 2019, retrofitting activities represented $54.4 \%$ of the building market in France [28]. For 2020, this activity is expected to increase $+0.9 \%$ [29].

Biomimicry offers an opportunity to handle retrofitting with a sustainable development perspective [14,23]. Nevertheless, only a few of the analyzed projects had partially retrofitted existing infrastructures. This topic deserves further exploration. The reasons could be related to a lack of research and practice of biomimicry for architectural and urban retrofitting but also, retrofitting projects and stakeholders could be less open to innovative approaches.

\section{Conclusions}

Biomimicry seems to be a design approach with growing interest in the French market, but several unresolved questions and challenges remain.

The analyzed data highlighted the gaps between biomimetic and biological research teams and urban designers practitioners. To facilitate the knowledge transfer from biological and ecological disciplines to architecture and urban design practice is a major challenge. Our data demonstrated the importance of rethink design team composition and projects design phase organization to bridge this gap.

The case studies also highlighted the variety of sustainability goals addressed through biomimicry in France. Nevertheless, it would be worth formally exploring the different urban stakeholders' motivations applying biomimicry and the difference in design process and outputs between applying it with a narrow or a broad focus.

Furthermore, it would also be essential to study and evaluate the performance of these projects concerning their objectives. Projects tend to use labels to show their performances, but urban biomimicry still lacks specific sustainable performance metrics. The use of life cycle assessments and ecosystems services assessments could allow a proxy to these performance assessments. 
Finally, to document and analyze the practice of biomimicry on architectural and urban projects allowed us to have some perspective from the French practice. To showcase national projects can tackle the incomprehension of biomimicry by urban stakeholders and project owners and raise awareness of the topic. Nevertheless, such benchmarks are rare and deserve to be enlarged. A more exhaustive study would probably highlight new challenges, and it remains relevant work to be done.

Supplementary Materials: The following are available online at https: / www.mdpi.com/article / 10.3390/biomimetics6020027/s1, Table S1: Projects data, Document S1: Projets urbains bio-inspirés: un état des lieux des projets français, Document S2: Variables and classification options definitions, Document S3: Leçons learned text excerpts.

Author Contributions: Conceptualization, E.B. and E.C.; methodology, E.B.; software, E.B.; validation, E.B., E.C. and C.L.; formal analysis, E.B.; investigation, E.B.; resources, E.B.; data curation, E.B.; writing-original draft preparation, E.B.; writing—review and editing, E.B., E.C., C.L., K.R. and P.C.; visualization, E.B.; supervision K.R. and P.C.; project administration, E.B.; funding acquisition, E.B., K.R. and P.C. All authors have read and agreed to the published version of the manuscript.

Funding: This research was funded by ANRT, grant number CIFRE 2019/0389.

Institutional Review Board Statement: Not applicable.

Informed Consent Statement: Not applicable.

Data Availability Statement: The data presented in this study are available in the Supplementary Materials.

Acknowledgments: We would like to thank the Biomim'City Lab and its external contributors for making the data analyzed in this study public available. We would also like to thank Caroline Robert, for the work gathering and organizing some of the information analyzed in this study.

Conflicts of Interest: The authors declare no conflict of interest. The funders had no role in the design of the study; in the collection, analyses, or interpretation of data; in the writing of the manuscript, or in the decision to publish the results.

\section{References}

1. ISO. ISO 18458:2015-Biomimetics-Terminology, Concepts and Methodology 2015; ISO: Geneva, Switzerland, 2015.

2. Pedersen Zari, M. Regenerative Urban Design and Ecosystem Biomimicry; Routledge: London, UK, 2018 ; ISBN 9781138079489.

3. Buck, N.T. The art of imitating life: The potential contribution of biomimicry in shaping the future of our cities. Environ. Plan. B Urban Anal. City Sci. 2017, 44, 120-140. [CrossRef]

4. Uchiyama, Y.; Blanco, E.; Kohsaka, R. Application of biomimetics to architectural and urban design: A review across scales. Sustainablility 2020, 12, 9813. [CrossRef]

5. Chayaamor-Heil, N.; Guéna, F.; Hannachi-Belkadi, N. Biomimétisme en architecture. État, méthodes et outils. Les Cah. Rech. Archit. Urbaine Paysagère 2018, 1. [CrossRef]

6. Hes, D.; Du Plessis, C. Designing for Hope: Pathways to Regenerative Sustainability; Routledge: New York, NY, USA, 2014; ISBN 9781138800618.

7. Pawlyn, M. Biomimicry in Architecture; RIBA Publishing: London, UK, 2016; ISBN 9781859466285.

8. European Commission. Towards an EU Research and Innovation Policy Agenda for Nature-Based Solutions \& Re-Naturing Cities. Final Report of the Horizon 2020 Expert Group on "Nature-Based Solutions and Re-Naturing Cities" (Full Version); European Commission: Brussels, Belgium, 2015; ISBN 978-92-79-46051-7.

9. Knippers, J.; Schmid, U.; Speck, T. Biomimetics for Architecture; Birkhäuser: Berlin, Germany; Boston, MA, USA, 2019.

10. Muséum National d'Histoire Naturelle. Bioinspire-Museum Document de Cadrage; Muséum National d'Histoire Naturelle: Paris, France, 2019.

11. Badarnah, L.; Kadri, U. A methodology for the generation of biomimetic design concepts. Archit. Sci. Rev. 2015, 58, 120-133. [CrossRef]

12. Ceebios. Projets Urbains Bio-Inspirés: Un état des Lieux des Projets Français; Ceebios: Senlis, France, 2020.

13. Ceebios Projet Urbain Bio-Inspiré-Rapport de Synthèse; Ceebios: Senlis, France, 2020.

14. Cruz, E.; Hubert, T.; Chancoco, G.; Naim, O.; Chayaamor-Heil, N.; Cornette, F.A.R.; Menezo, C.; Badarnah, L.; Raskin, K. Design processes and multi-regulation of biomimetic building skins: A comparative analysis. Energy Build. 2021. under review.

15. Kuru, A.; Oldfield, P.; Bonser, S.; Fiorito, F. A framework to achieve multifunctionality in biomimetic adaptive building skins. Buildings 2020, 10, 114. [CrossRef]

16. Hayes, S.; Desha, C.; Gibbs, M. Findings of case-study analysis: System-Level biomimicry in built-environment design. Biomimetics 2019, 4, 73. [CrossRef] [PubMed] 
17. Groat, L.; Wang, D. Architectural Research Methods; John Wiley \& Sons: Hoboken, NJ, USA, 2013; ISBN 9780470908556.

18. Krippendorff, K. Content Analysis: An Introduction to its Methodology, 2nd ed.; Sage Publications: Thousand Oaks, CA, USA, 2004; ISBN 0761915443.

19. Graeff, E.; Maranzana, N.; Aoussat, A. Biomimetics, where are the biologists? J. Eng. Des. 2019, 30. [CrossRef]

20. Graeff, E.; Maranzana, N.; Aoussat, A. Engineers' and biologists' roles during biomimetic design processes, towards a methodological symbiosis. In Proceedings of the International Conference on Engeenering Design ICED 2019, Delft, The Netherlands, 5-8 August 2019; pp. 319-328. [CrossRef]

21. Wanieck, K.; Fayemi, P.E.; Maranzana, N.; Zollfrank, C.; Jacobs, S. Biomimetics and its tools. Bioinspired Biomim. Nanobiomaterials 2017, 6, 53-66. [CrossRef]

22. Blanco, E.; Pedersen Zari, M.; Raskin, K.; Clergeau, P. Urban Ecosystem-Level Biomimicry and Regenerative Design: Linking Ecosystem Functioning and Urban Built Environments. Sustainability 2021, 13, 404. [CrossRef]

23. Pedersen Zari, M.; Hecht, K. Biomimicry for regenerative built environments: Mapping design strategies for producing ecosystem services. Biomimetics 2020, 5, 18. [CrossRef] [PubMed]

24. Rovalo, E.; McCardle, J.; Smith, E.; Hooker, G. Growing the practice of biomimicry: Opportunities for mission-based organisations based on a global survey of practitioners. Technol. Anal. Strateg. Manag. 2019, 32, 71-87. [CrossRef]

25. Busby Perkins+Will. Stantec Consulting. In Roadmap for the Integrated Design Process; BC Green Building Roundtable: Vancouver, BC, Canada, 2007.

26. Blanco, E. Biomimétisme: Inspirer nos villes des systèmes vivants. In Urbanisme et Biodiversité; Clergeau, P., Ed.; Editions Apogée: Rennes, France, 2020.

27. Attia, S.; Eleftheriou, P.; Xeni, F.; Morlot, R.; Ménézo, C.; Kostopoulos, V.; Betsi, M.; Kalaitzoglou, I.; Pagliano, L.; Cellura, M.; et al. Overview and future challenges of nearly zero energy buildings (nZEB) design in Southern Europe. Energy Build. 2017, 155, 439-458. [CrossRef]

28. FFB. Le Bâtiment en Chiffres 2019; FFB: Paris, France, 2020.

29. FFB Bilan. Bilan 2019 et Prévisions 2020; FFB: Paris, France, 2019. 